\title{
ACUPUNCTURE THERAPYY TO REDUCE CONSTIPATION: META-ANALYSIS
}

\author{
Muslihatin Khuril Rosyida \\ Masters Program in Public Health, Universitas Sebelas Maret
}

\begin{abstract}
Background: Pharmacologic agents, such as stimulants or lubricant laxatives, often used to relieve the constipation. However, it can induce abdominal pain, bloating, watery stools, and fecal incontinence. In addition, long-term use of stimulant laxatives may result in adverse effects, such as melanosis coli and cathartic colon. There is a need on nonpharmacologic approach to overcome constipation. This study aimed to examine the effect of acupuncture therapyy to reduce constipation using meta-analysis.

Subjects and Method: A systematic review and meta-analysis was conducted by PRISMA flow diagram. The articles were collected from Google Scholar, Pubmed, and Science Direct databases. Keywords used "Acupuncture" AND "Constipation", "Acupuncture for constipation" AND "RCT". Eligibility criteria were defined using the PICO model as follows, (1) population: patients with constipation, (2) intervention: acupuncture therapy, (3) comparison: sham acupuncture, and (4) outcome: constipation. The inclusion criteria were full text randomized controlled trial published from year 2011 to 2021. Articles that met the criteria were analyzed by Revman 5.3.

Results: 6 randomized controlled trial from China and Korea were included in this meta analysis. This study found that acupuncture therapy was effective to reduce constipation (Standardized Mean Difference $=-1.40 ; 95 \% \mathrm{CI}=-2.74$ to $-0.06 ; \mathrm{p}=0.040$ ). $\mathrm{I}^{2}=99 \%$ represent high heterogeneity between studies. Therefore, the random effects model was used to combine the studies' results.
\end{abstract}

Conclusion: Acupuncture therapy was effective to reduce constipation.

Keywords: acupuncture, constipation, randomized control trial

\section{Correspondence:}

Muslihatin Khuril Rosyida. Masters Program in Public Health, Universitas Sebelas Maret. Jl. Ir. Sutami 36A, Surakarta 57126, Central Java. Email: khurilrosyida@gmail.com. Mobile: 08564713149. 